\title{
A parkinsonian syndrome in the course of subacute encephalitis
}

M. J. MOSSAKOWSKI, M.D.,

AND

G. MATHIESON, M.B., Ch.B. 
Volume $11 \cdot$ Number 6

\title{
A parkinsonian syndrome in the course of subacute encephalitis
}

\author{
M. J. Mossakowski, M.D., and G. Mathieson, M.B., Ch.B.
}

EXTMAPYRAMIDAL SYNDHOMEs form an essential element of the clinical picture of the subacute encephalitides of van Bogaert, Dawson, and Pette and Doring types. ${ }^{1-6}$ They occur in the second phase of the disease, diminishing gradually with the increase of generalized decorticate rigidity which is typical of the terminal stage. These extrapyramidal syndromes usually take the form of simple or complex hyperkinesias. Muscle hypertonus is probably also partly extrapyramidal in origin during the second stage of the illness. Despite the remarkable variability of extrapyramidal syndromes occurring with the subacute encephalitides, a parkinsonian syndrome is rare. In the literature dealing with these 3 types of subacute encephalitis, we found only 1 case in which a parkinsonian syndrome temporarily dominated the clinical picture.

We consider the following case of subacute sclerosing leukoencephalitis of van Bogaert interesting in that, during one phase of the disease, the patient showed a prominent parkinsonian svndrome. At one time, this was so dominant that the first diagnostic impression was "postencephalitic parkinsonism." However, the further course of the illness, including the development of a hyperkinetic syndrome char- acterized by rhythmic myoclonic jerks, and additional examinations such as electroencephalography and brain biopsy led to a correct diagnosis being established during the patient's life.

\section{CLINICAL HISTORY}

Mary P., age 11, was under clinical observation in Montreal Neurological Institute from March 11 to April 10, 1959. She was the second child in a sibship of 5 . Her parents were young and healthy. There was no record of nervous or mental disease in the families of the father and mother. The siblings, 2 brothers and 2 sisters, were healthy and were of normal physical and mental development. The patient was born after a normal, full-term pregnancy. Delivery and early development were also normal. She started to walk at about 1 year and to speak between 2 and 3 .

In September 19.58, she had a brief illness called "flu," after which some slight, but gradually increasing change in her personality

From the Department of Neurology and Neurosurgery, McGill University, Montreal, and Montreal Neurological Institute.

Dr. Mossakowski is a fellow of the Polish Academy of Sciences, Warsaw 
developed. She cried easily and became disorderly and much less efficient in her school work. She became withdrawn and had some difficulty in her contacts with other children. Difficulty in learning increased rapidly so that, after two months, she was unable to continue at school. At the same time, marked slowness in movement and speech developed. Her gait became unsteady, and she often fell. She was unable to dress herself. Very often, she seemed to be in a "daze," and it was necessary to repeat questions several times before she noticed that she was being spoken to.

At the end of January 1959, rhythmic tremor of the hands was superimposed on the background of generalized motor slowness and marked mental deterioration. The tremor increased in extent and amplitude when she was excited. At the same time, difficulty in speaking developed; she did not speak spontaneously and answered questions with monosyllables. Her speech was slightly dysarthric. She had difficulty in swallowing.

In February 1959, she was admitted briefly to St. Rita's Hospital, Sydney, Nova Scotia. The outstanding neurologic abnormality found there was rigidity of all limbs and rhythmic tremor of both hands, increasing during voluntary movements. After discharge from hospital, her condition became worse. She was confined to bed, being scarcely able to walk; she was also unable to feed herself (Dr. Anne Earle).

Physical examination on admission to Montreal Neurological Institute on March 11, 1959, showed her to be well nourished and well developed. General physical examination was noncontributory. She lay in bed with an expressionless face and both hands drawn into the "main d'accoucheur" position. Her voice was high-pitched, monotonous, and indistinct. She was unable to carry out simple mental arithmetic, and there was other evidence of mental deterioration. The ocular fundi were normal. She had difficulty in swallowing and drooled saliva. Tone was increased in all muscle groups, with a cogwheel type of rigidity; this feature was more marked in the left arm and left leg. A pill-rolling tremor was present in both hands, more marked on the left, and was exaggerated by emotional stress. During voluntary movements such as closing the eyes, flexing the chin to the chest, and raising the head and shoulders, there was a generalized, violent tremor involving the whole body. Tendon reflexes were increased in both legs, and there was bilateral ankle clonus, but the plantar responses were flexor. No clear-cut evidence of cerebellar dysfunction was found. No sensory disturbance could be demonstrated.

During her stay in hospital, she remained confined to bed. With trihexyphenidyl (Artane) therapy, there was some improvement in her condition; her voice became stronger, swallowing improved, and drooling of saliva decreased. At the end of her first week in hospital, the clinical pattern changed dramatically. Tremor at rest, which had been a very prominent feature, disappeared completely. The rigidity changed, becoming more "lead pipe" than "cogwheel" in type. At about the same time, myoclonic jerks were seen for the first time; in these, both arms were raised, the eyelids blinked, and the legs were extended. Her muscle hypertonus continued to increase, so that by the third hospital week she was able to perform only very limited voluntary movements. Myoclonic jerks increased in frequency and severity. She was discharged on April 10, 1959. Thereafter, her condition rapidly deteriorated and she died twelve days later, eight months after the onset of her final illness.

Laboratory investigations. The urine was free from phenylketones, and metachromatic bodies were not found on microscopic examination. Hematologic and biochemical studies showed no significant abnormality. Cerebrospinal fluid was at normal pressure and clear and contained $26 \mathrm{mg}$. per cent protein and 2 lymphocytes per cubic millimeter; the Lange read 5533210000. Plain roentgenograms of the skull showed no abnormality. A pneumoencephalogram showed slight symmetric enlargement of the lateral ventricles.

On electroencephalograms (Fig. 1) made March 11, 1959, the most striking abnormality was seen in the sleep record. This consisted of bilaterally synchronous, high-voltage sharp waves, maximum in anterior head regions, interrupted by stretches of low-voltage activity. The sharp waves often occurred in groups separated by stretches of low-voltage activity, the pattern resembling that described as a suppression-burst activity. Sometimes, instead of bursts of sharp waves, there were bursts 


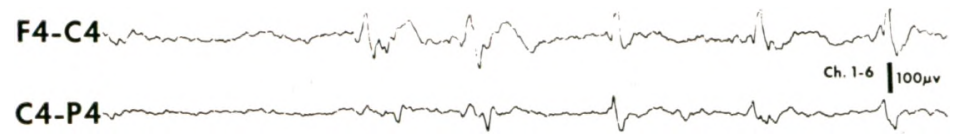

P4-O2

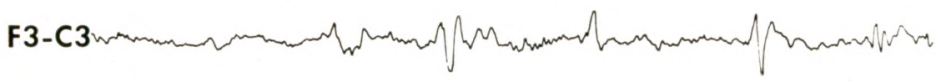

C3-P3
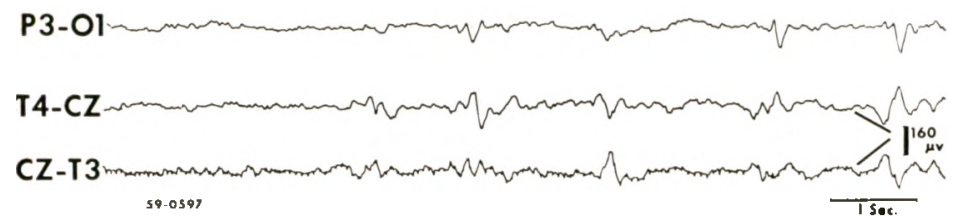

Fig. 1. Sample of first electroencephalogram (March 11, 1959). Bipolar recording on Grass 8-channel machine. F4-C4=Right midfrontal to right midcentral. C4-P4= Right midcentral to right midparietal. $\quad \mathrm{P} 4-\mathrm{O} 2=$ Right midparietal to right occipital. F3-C3 $=$ Left midfrontal to left midcentral. $\mathrm{C} 3-\mathrm{P} 3=$ Left midcentral to left midparietal. P3-Ol=Left midparietal to left occipital. T4$\mathrm{CZ}=$ Right midtemporal to central vertex. CZ-T3 $=$ Central vertex to left midtemporal of slow waves, or slow and sharp waves mixed together. During wakefulness, the activity was not quite so severely disturbed but was still abnormal, with some bilateral, synchronous, high-voltage, slow and sharp wave discharges and some disturbance of regulation of cortical rhythms. These findings indicated the presence of diffuse, bilateral, brain abnormality involving cortical and subcortical structures.

A subsequent electroencephalogram on April 3 (Fig. 2) showed a definite deterioration, indicating a marked progression of the disease. In the waking stage, the background activity was rather flat with some rapid rhythms but hardly any alpha activity, which was reduced to insignificant remnants in the occipital region. Superimposed upon this background were bursts of bilateral, synchronous, irregular, high- voltage slow waves which occurred at intervals varying between about eight and sixteen seconds. Occasionally, some sharp wave discharges were associated with these slow waves. The paroxysmal slow wave discharges were associated with generalized movements of the limbs only in the waking state, although the paroxysmal slow wave discharges still occurred during sleep when movements were absent. In contrast to the first tracing, the second electroencephalogram in the waking state showed more abnormality than during sleep. During sleep, there were some remnants of normal potentials, whereas the background activity during wakefulness was entirely abnormal. The electroencephalographic pattern was considered to be typical of inclusion body encephalitis or the van Bogaert type of sub-
Fig. 2. Sample of second electroencephalogram (April $3,1959)$. Technical data as in Figure 1

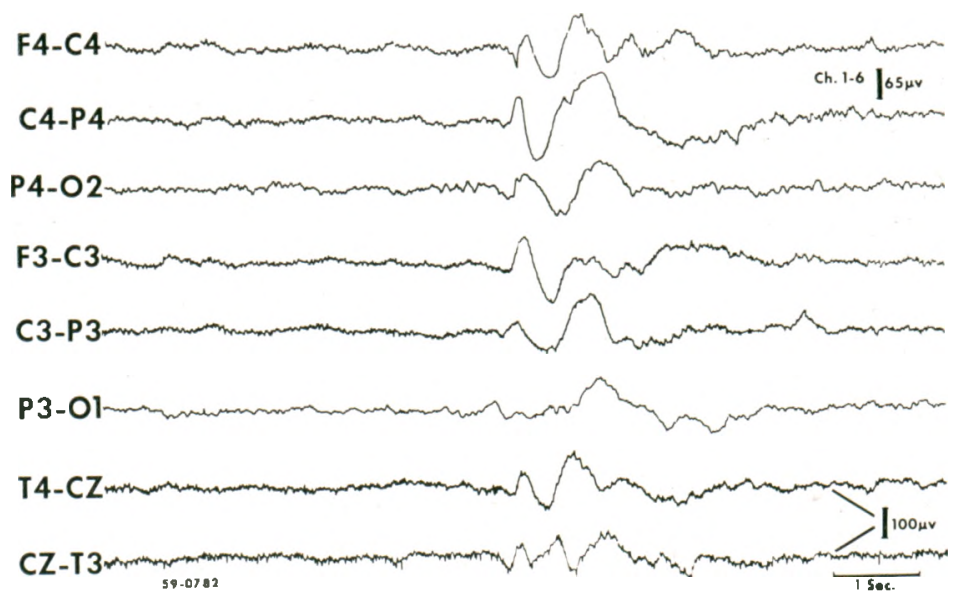


acute sclerosing leukoencephalitis (Dr. Peter Gloor).

Brain biopsy was carried out on March 18. The specimen, from the left parietooccipital region, contained both cortex and subcortical white matter. Perivascular infiltration by lymphocytes and some plasma cells in both the cortex and white matter was seen, more profuse in the white matter. Diffuse proliferation of microglial cells was noted throughout the cortex; most of them had hypertrophied, rodshaped nuclei. Also, slight astrocytic proliferation was found, mainly in the deeper cortical layers. Most of the neurons appeared normal, but there were some rare examples of shrinkage and disintegration of neurons associated with satellitosis. Inclusion bodies were not seen. In the white matter, there was diffuse fibrogliosis associated with hypertrophy of astrocytes. Myelin damage was not seen. No metachromatic deposits were found in the white matter. The histopathologic features were those of subacute encephalitis, and the preferential involvement of the white matter favored the diagnosis of van Bogaert's subacute sclerosing leukoencephalitis.

Virologic studies by Dr. A. M. Masson of the blood, cerebrospinal fluid, stool, and brain specimen were negative.

\section{PATHOLOGIC OBSERVATIONS}

General autopsy was carried out in St. Rita's Hospital in Sydney, Nova Scotia, by Dr. A. W. Cyorfi, to whom we are indebted for the pathologic material. The trunk organs showed no significant abnormality on gross examination. Microscopic examination showed only patchy areas of terminal bronchopneumonia bilaterally.

The brain was small but symmetric and normal in form externally. However, there was marked firmness of the cerebrum, cerebellum, and brain stem. On section, no focal lesion was seen other than at the site of biopsy. Demyelination could not be detected on naked eye examination. The substantia nigra appeared wholly unpigmented. The locus coeruleus could be made out but was only very faintlv pigmented. The basal ganglia, thalamus, subthalamic nuclei, dentate nuclei, and inferior olives appeared normal. The ventricular system was not dilated.

Histopathology of the brain. The leptomeninges contained discrete perivascular cuffs of lymphocytes and plasma cells. The cortex showed diffuse, inflammatory change occurring mainly in the form of perivascular infiltrates, which were, however, not profuse, being confined to 3 or 4 layers of lymphocytes and plasma cells surrounding small, otherwise normal, cortical blood vessels (Fig. 3). Although perivascular infiltration was present throughout the cortex, it tended to occur mainly in the deep cortical layers and at the corticalwhite matter junction. There was intense microglial proliferation both diffuse and nodular, the latter involving mainly the deeper cortical layers (Fig. 4), Moderate prolifer-

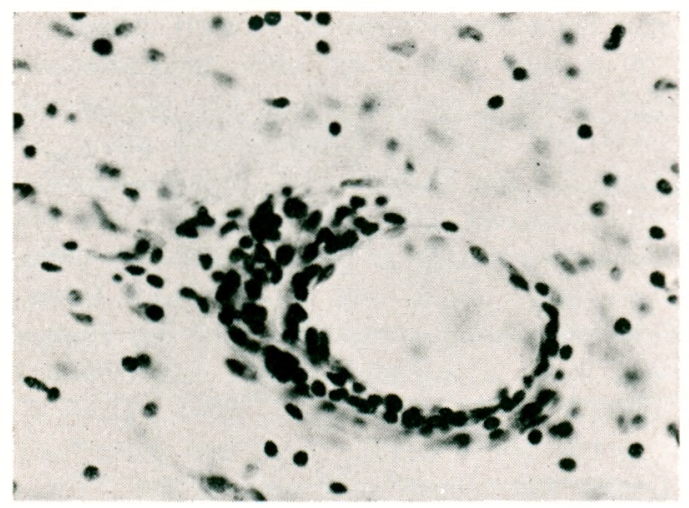

Fig. 3. Right temporal cortex showing venule surrounded by lymphocytes and plasma cells. Cresyl violet stain. $x: 360$

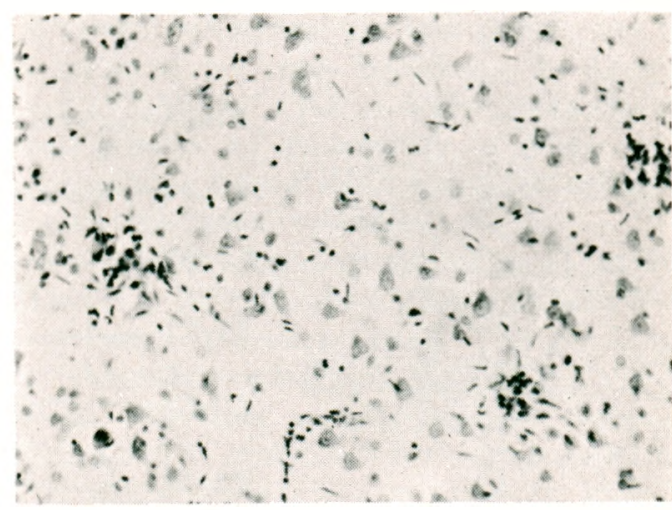

Fig. 4. Right temporal cortex showing diffuse and nodular microglial proliferation. Cresyl violet stain. $\times 120$ 
ation of fibrillary astroglia was also seen, occurring mainly near the junction of cortex and white matter. Neurons were but little involved; there was, however, slight patchy neuronal loss in all cortical layers, perhaps more definite in the third and fifth lavers. Some neurons showed shrinkage and hyperchromatism of the cell body or chromatolysis, the latter change being more common. Neither intranuclear nor cytoplasmic inclusions were found. These features were present in all cortical regions; temporal and parietal cortex were most involved, frontal and insular least.

The cerebral white matter also showed perivascular infiltration with lymphocytes and plasma cells; these were more intense than in the cortex. The left temporal and parietal lobes seemed to be most severely involved. The myelin picture in most areas appeared normal, but, in the anterior limb of the internal capsule, there was some patchy pallor of myelin and, in the left occipital lobe, several small, ill-defined foci of myelin breakdown were present. In some of these the myelinated fibers of the cortex were also involved. In the areas of myelin damage, Sudan IV stained frozen sections showed fine, granular, sudanophilic deposits lying free in the tissue and occasionally accumulated in perivascular spaces. There were only occasional fat-laden macrophages.

Diffuse, dense fibrogliosis of the whole cerebral white matter was the most prominent feature histopathologically (Fig. 5). This fibrogliosis was out of proportion to the myelin damage and occurred in many places where myelin appeared entirely normal. It reached its greatest intensity in the temporal and parietal lobes and in the extreme and external capsules. The internal capsules and the corpus callosum were only slightly involved. Some proliferation and hypertrophy of microglial cells were also seen in the white matter, but only occasional small nodules and glial stars were observed here.

Perivascular inflammatory sleeves were prominent in the striatum, pallidum, and nucleus subthalamicus Luysii. There was some diffuse and nodular microglial proliferation in these structures, but it was less in degree than in the cortex. Several putaminal neurons appeared pale, but there was no definite neuronal loss or fibroglial proliferation here. Severe

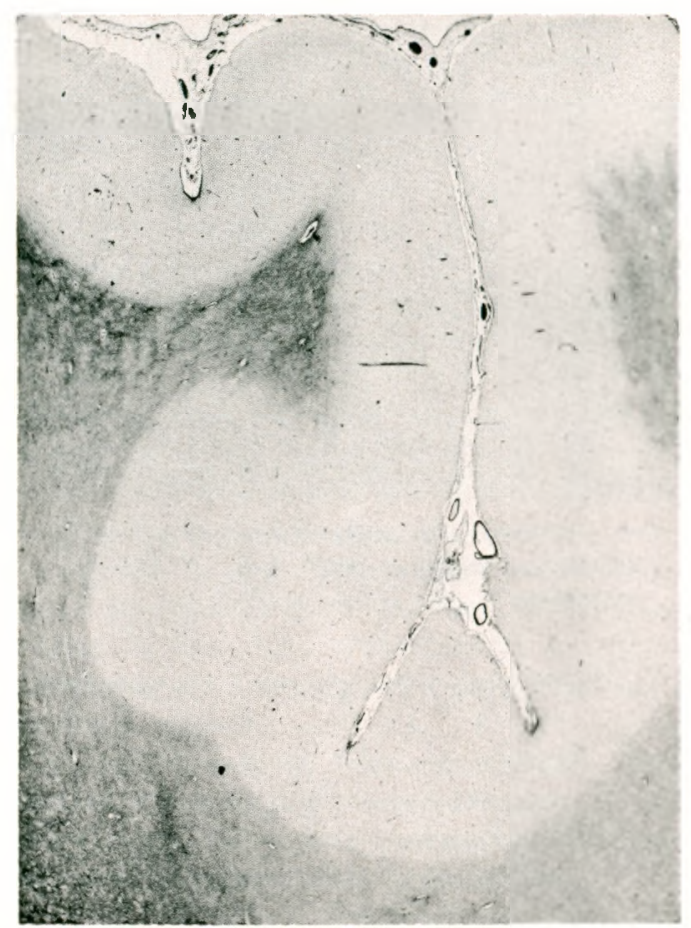

Fig. 5. Left frontal lobe showing diffuse fibrogliosis of white matter. Holzer's method. $\times 5$

pathologic changes were seen in the thalamus and lateral geniculate bodies. These structures, besides perivascular cuffs and diffuse and nodular microglial proliferation, showed severe neuronal loss and accompanying fibrogliosis. Severe damage of the substantia nigra was the ontstanding pathologic change in the midbrain. This structure had lost many of its neurons, especially in its lateral and central groups (Fig. 6), while the medial group appeared more or less normal. The surviving nigral neurons showed various signs of damage; many were shrunken, deformed, or fragmented (Fig. 7), and others showed pigment loss and tigrolysis. Melanin granules lay free in the tissue, but phagocytosis of melanin was not a feature. The neuronal loss had produced much rarefaction of the tissue, the small holes resulting from the disappearance of neurons being surrounded by microglial cells. There were rare examples of neuronophagia. These parenchymal changes were accompanied by marked astrocytic and microglial proliferation, the former being more intense. Holzer stain 


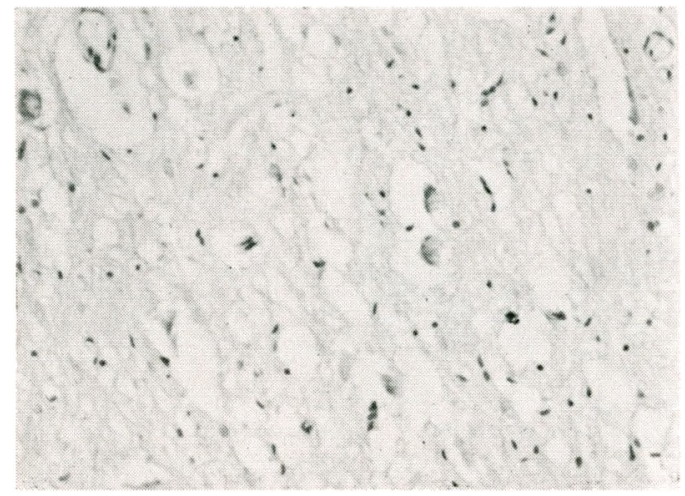

Fig. 6. Substantia nigra showing fenestration of tissue resulting from loss of neurons. Hematoxylin and eosin. $\times 110$

revealed selective fibrogliosis of the substantia nigra (Fig. 8). All these changes involved both rostral and caudal portions of the substantia nigra. The rest of the midbrain, including the red nucleus and tectal region, was the site of minimal perivascular cuffing accompanied by moderate microglial proliferation. The tegmental portion of the pons presented a similar picture, while more abundant perivascular infiltration, microglial proliferation, and some neuronal loss were seen in the basal portion of the pons. The locus coeruleus showed a normal neuronal population with slight glial proliferation.

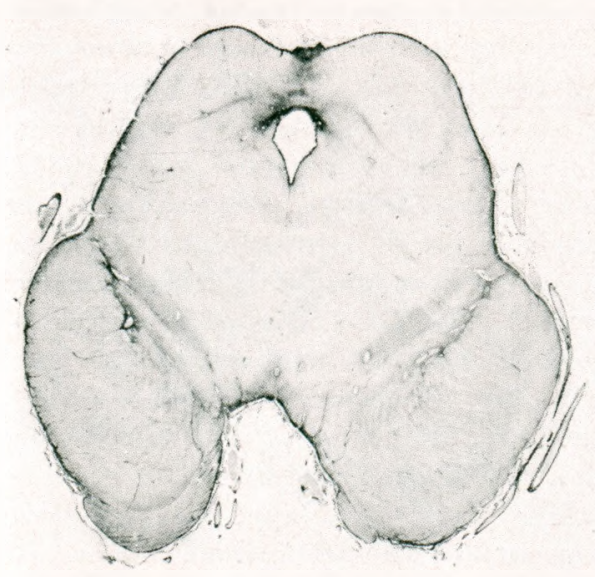

Fig. 8. Midbrain showing selective fibrogliosis in central and lateral groups of substantia nierat. Holzer's method. $\times 2.3$

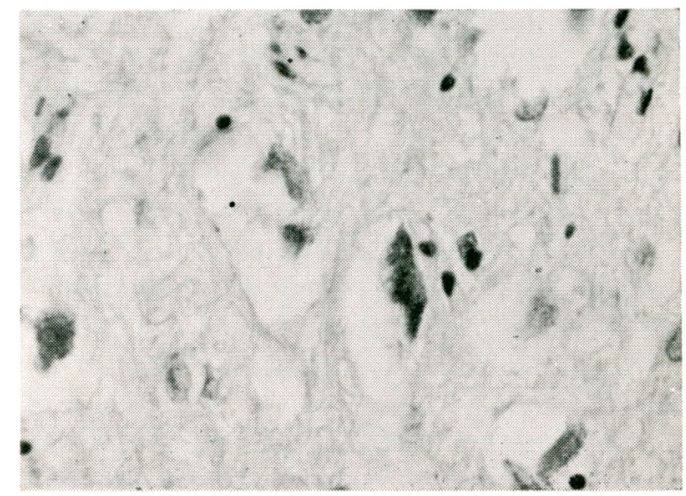

Fig. 7. Substantia nigra, higher magnification, showing damage to residual neurons.

Hematoxylin and eosin. $\times 360$

The medulla appeared normal apart from minimal perivascular infiltration in the subependymal region and isolated microglial nodules in the inferior olives. In the cerebellum, scanty perivascular cuffs and nodular glial proliferation in the dentate nuclei were accompanied by moderate fibrogliosis of the white matter.

In summary, the brain showed widespread inflammatory features. Fibrogliosis out of proportion to the myelin damage had occurred in the cerebral white matter. The substantia nigra was severely damaged, while, more caudally, changes were slight. Neither neuronal nor glial inclusion bodies were found. A diagnosis of subacute sclerosing leukoencephalitis of van Bogaert type was made.

\section{DISCUSSION}

According to the accounts of van Bogaert, Brain, and others, 3 main phases are distinguishable in the disease. At the onset, impaired intellectual ability and abnormalities of behavior occur and gradually progress, so that latterly there is profound dementia. The second phase of the illness is dominated by motor disturbances in the form of extrapyramidal syndromes. Finally, the patient passes into a decorticate state. In our case, the second period of the disease presented an interesting and unusual picture. In this phase of extrapyramidal symptomatology, we can distinguish 2 well defined subphases. During the first of these, lasting approximately two months, there was a striking parkinsonian syndrome which 
later disappeared, being replaced in the second phase by a hyperkinetic syndrome dominated by generalized, myoclonic discharges. The earlier clinical picture presented the complete triad of parkinsonian symptomatologyakinesia, muscular rigidity of cogwheel type, and tremor at rest. There were, however, no oculogyric crises or vegetative disturbances, but difficulty in articulation and swallowing occurred. It is noteworthy that all these symptoms improved with medication. In addition to the tvpically parkinsonian rest tremor, we observed some intention tremor. Carpenter pointed out the difficulty in separating these 2 types of tremor in the course of Parkinson's syndrome, the tremor at rest often being accompanied by one of intention type. The generalized irregular trembling of the patient's whole body, which occurred during some voluntary movements, was, in our opinion, a quite different clinical phenomenon. We consider it to be a particular form of the generalized motor discharges described by Macken and Lhermitte, ${ }^{9}$ Martin and Isler, ${ }^{10}$ and Weingarten and Seitelberger. ${ }^{\top}$

While many different extrapyramidal symptoms have been described with the subacute encephalitides and the individual elements of Parkinson's syndrome are commonly reported, a fully established parkinsonian syndrome is rare. We have reviewed the literature on subacute encephalitis from this point of view. In 66 cases of sclerosing leukoencephalitis of van Bogaert culled from the literature $e^{1, \pi, 9-24}$ and in 1 previous unpublished case of our own, 21 patients had some form of tremor. Unfortunately, in most cases, the precise characteristics of the tremor were not described. In some cases, ${ }^{7,9,10}$ the tremor occurred in the form of local or generalized paroxysmal motor discharges. In 1 case published by Corsellis ${ }^{14}$ and in 1 of the Poser and Radermecker series, ${ }^{19}$ the tremor was described as being of intention type. In 4 cases (those of Macken and Lhermitte ${ }^{9}$ and Weingarten and Seitelberger ${ }^{7}$ ), a parkinsonian type of tremor occurred. In 24 published cases of subacute inclusion encephalitis of Dawson type, ${ }^{3-5,25-29} 7$ were described as having tremor; in 3 , the tremor was not clearly described, and, in $2,{ }^{13,26}$ the tremor was parkinsonian in type, occurring at rest and disappearing during voluntary movement. In
29 cases of panencephalitis nodosa, 2 patients (both from Kalm's series ${ }^{32}$ ) are described as having tremor; in each, the tremor occurred at rest.

Muscular hypertonus is a constant clinical feature in the course of subacute encephalitis. According to most authors, it is partly extrapyramidal in nature, but Foley and Williamsio have emphasized that rigidity of classical parkinsonian type is exceptional. Akinesia, the third major element of Parkinson's syndrome, is probably complex in origin. Poverty of facial expression, commonly seen with sclerosing leukoencephalitis, ${ }^{1,10.13^{*}}$ subacute inclusion encephalitis, ${ }^{3,13}$ and panencephalitis nodosa, ${ }^{6}$ could be attributed to akinesia of a parkinsonian nature, but, undoubtedly, in many cases mental changes play a part in its production.

In only 1 case of subacute sclerosing leukoencephalitis, that of Weingarten and Seitelberger, ${ }^{7}$ have all 3 parkinsonian elements been observed together. They occurred in a 13year-old girl with a clinical diagnosis of parkinsonism. She was observed by the authors themselves only in the terminal period of the disease when the parkinsonian features had disappeared, and all information about the earlier symptomatology was indirect. In all other cases of subacute sclerosing leukoencephalitis that we found in the literature, only some elements of the parkinsonian syndrome were observed as discussed above. The same is true of cases of inclusion body encephalitis $^{3,4}$ and of panencephalitis nodosa. ${ }^{3.2}$

Histopathologic examination in our case revealed much damage to the substantia nigra. This was especially severe in the lateral and middle neuronal groups of the nucleus, while the medial group was relatively spared. This distribution of lesions corresponds in general to that described by Hassler ${ }^{39}$ as typical of "idiopathic" Parkinson's disease. It seems reasonable, therefore, to attribute the parkinsonian syndrome in our case to involvement of this structure. The substantia nigra is commonly involved in subacute sclerosing leukoencephalitis. Guazzi, ${ }^{40}$ studying the topography of lesions in the brain stem in 50 cases at the Institute Bunge, found severe neuronal loss in the substantia nigra in 14 cases. Nevertheless, none of these patients manifested a 
pure parkinsonian syndrome clinically. ${ }^{+1}$ Similarly, of the 24 patients with subacute inclusion encephalitis reviewed above, $9 \mathrm{had}$ changes in the substantia nigra. In panencephalitis nodosa, 7 of 29 cases in the literature had nigral lesions, although in this condition neuronal destruction was less marked. The question arises then, why, with nigral lesions so frequent in subacute encephalitis, has a parkinsonian syndrome been seen in only 1 previous case and what factor determined its occurrence in this present case? It is probable that the disease process must involve a sufficiently large proportion of the neuronal population of the nucleus before the clinical syndrome becomes manifest. This in itself does not appear to be an adequate explanation, as in many cases without parkinsonian features the nigral lesion has been described as severe. We believe that parkinsonian symptomatology will only occur in cases in which sufficiently severe damage to the substantia nigra (or related structures) takes place early in the course of the disease. In those cases in which nigral damage occurs late, after other structures producing hyperkinetic symptoms have been damaged, the alteration of the substantia nigra can be clinically mute, masked by hyperkinetic symptomatology. The histopathologic changes, especially the intense fibrogliosis, in our case indicate that the damage to the substantia nigra occurred rather early in the course of the disease. Liter involvement of other structures of the central nervous system caused the dramatic change in the clinical picture.

The converse situation in which a parkinsonian syndrome $\bar{i}$ or prominent elements of this syndrome ${ }^{9,13}$ occur in subacute scleros- ing leukoencephalitis without a nigral lesion calls for comment. These cases can only be explained by supposing that extranigral lesions are responsible for the parkinsonian features. That such an event may occur is supported by the observations of Coërs, Kleyntjens, and Brihaye $^{4-2}$ on parkinsonian symptoms in cases of intracranial tumor in which the substantia nigra was intact. Recently, Dr. J. Gybels in our department has studied a case of sphenoidal ridge meningioma presenting exactly these features.

The question of similarities and differences and of possible essential identity of the different forms of the subacute encephalitides has been discussed by the majority of authors quoted and others ${ }^{43-45}$ on clinical, electroencephalographic, and pathologic grounds. Considering the almost indistinguishable clinical picture and very similar pathologic changes in the 3 forms of subacute encephalitides, we agree with the widespread opinion that further morphologic discussion on their identity or otherwise will not solve the problem. Only etologic data will answer this question.

\section{SUMMARY}

1. A clinical and pathologic account of a case of subacute sclerosing leukoencephalitis of van Bogaert with a prominent Parkinson's syndrome at one stage of the illness is presented.

2. The morphologic basis of this clinical syndrome, rare in the course of subacute encephalitis, is discussed and the relevant literature reviewed.

The authors are indebted to Dr. Francis McNaughton and Dr. Ludo van Bogaert for their interest and advice.

\section{REFERENCES}

1. Van Bogakht, L.: Une leuco-encéphalite sclérosante subaiguë. J. Neurol., Neurosurg. \& Psychiat. 8:101, 1945.

2. van Bogaknt, L.: Sur une leuco-encéphalite sclérosanto subaiguë (deuxieme mémoire). Rev, neurol. 87: 1, 1952 .

3. Dawson, J. R.: Cellular inclusions in cerebral lesions of lethargic encephalitis. Am. J. Path. 9:1, 19.3.3.

4. Dawson, J. R.: Cellular inclusions in cerebral lesions of epidemic encephalitis. Arch. Neurol. \& Psychiat, 3I: 685, 1934

5. Braix, W. R., Greenfield, J. G., and Russelr, D. S.: Subacute inclusion encephalitis (Dawson type). Brain $71: 365,1948$.
6. Pette, H., and Döring, G.: ther einheimische Panencephalomyelitis vom Character des Encephalitis japonica. Deutsche Ztschr. Nervenh. 149:7, 1939.

7. Weingahten, K., and Seitelberger, F.: Uher die subakute sklerosierende Leuko-encephalitis. Wien. Ztschr. Nervenh. 6:65, 1952 .

8. Carpenter, M. B.: The neuroanatomic basis of dyskinesia. In Pathogenesis and Treatment of Parkinsonism, edited by W. S. Fields. Springfield, Ill., Charles C Thomas, 1958, pp. 50-8.5.

9. Macken, J., and Lhermitte, F.: Etude clinique et anatomique de la "leuco-encéphalite sclérosante subaiguë." Sa place parmi les encéphalites. Bull. Acad. roy méd. Belgique $15: 205 ; 263,1950$. 
10. Martin, F., and Isler, W.: Recherches complementaires sur la leucoencéphalite sclérosante subaiguẻ. Trois observations anatomo-cliniques nouvelles. Schweiz. Arch. Neurol. Psychiat. 79:112, 1957.

11. Myle, G., and van Bogaent, L.: Des hypercinésies cloniques uni-puis bilatérales dominant le tableau neurologique de la leuco-encéphalite sclérosante subaiguë. Acta neurol, et psychiat. belg. 49:787, 1949.

12. Dubois, R., yan Bogaert, L., and Lhermitte, F.: Deux nouvelles observations de leuco-encéphalite sclérosante subaiguë. Acta neurol. et psychiat. belg. 49:762, 1949 .

13. Greenfield, J. G.: Encephalitis and encephalomyelitis in England and Wales during the last decade. Brain 73:141, 1950 .

14. Martin, F., Macken, J., and Hess, R.: Sur une encéphalite subaiguë, ayant les caractères de la leucoencéphalite sclérosante, avec inclusions. Schweiz. Arch. Neurol. u. Psychiat. 66:217, 1950.

15. Consellis, J. A. N.: Sub-acute sclerosing leucoencephalitis: a clinical and pathological report of 2 cases. J. Ment. Sc. $97: 570,1951$

16. Егске, W. J.: tber die Leukoencephalitis. Nervenarzt $22: 241,1951$.

17. Brügger, A.: Uber eine Encephalitis subacuta sclerosans (van Bogaert/Pette-Döring). Schweiz. Arch. Neurol. 1. Psychiat. $77: 139,1956$.

18. Hamoen, A. M., Hehngheen, H., Stokm van Leevwes, W., and Magnus, O.: Encéphalite subatiguë progressive. Constatations cliniques et électroencéphalographiques dans 23 cas. Rev. neurol. $94: 109,1956$.

19. Poser, C. M., and Ranermecker, J.: Subacute sclerosing leukoencephalitis. J. Pediat. 50:408, 1957.

20. Bнuснен, J. M., and Dechef, G.: Etude anatomoclinique d'un cas de leucoencéphalite sclérosante subaiguë. Acta neurol. et psychiat. belg. 57:775, 1957.

21. Wender, M.: Leucoencéphalite sclérosante subaiguë de l'adulte. Rev. neurol. $97: 285,1957$.

22. Cramer, R., and Gutewa, J.: Uber einen Fall von subakuter sklerosierender Leukoencephalitis van Bogaert. Helvet. paediat. acta $8: 152,1953$.

23. Kalab, Z., Kostelnik, J., and Pospisil, L.: Ein Fall subakuter sklerosierender Leukoencephalitis van Bogaert mit virologischer Untersuchung. Psychiat., Neurol. u. med. Psychol. 10:26.5, 1958.

24. Pere, S., Perier, J. O., and Quersin, L.: Documents cliniques, anatomiques et experimentaux concernant lencéphalite subaiguë type van Bogaert. Arch. françpédiat. 15:981, 1958

25. Mai amud, N Haymaker, W., and Pingehton, H, Inclusion encephalitis with elinicopathologic report of 3 cases. Am. J. Path. 26:133, 1950

26. Foley, J., and Williams, D.: Inclusion encephalitis and its relation to subacute sclerosing leucoencephalitis. Quart. J. Med. 22:157, 1953.

27. Van Bures, J. M.: A case of subacute inclusion encephalitis studied by the metallic methods. J. Neuropath. \& Exper. Neurol, 13:230, 1954.
28. Landau, W. H., and Luse, S. A.: Relapsing inclusion encephalitis (Dawson type) of eight years' duration. Neurology 8:669, 1958.

29. Rende-Shont, J.: Two cases of subacute inclusion body encephalitis (van Bogaert's encephalitis). Proc. Roy. Soc. Med. 52:299, 1959.

30. Mïller, W.: Zur Frage der Panencephalitis. Ztschr, f. d. ges. Neurol, u. Psychiat. 174:564, 1942.

31. Baltuasah, K.: Zur Kenntnis der Panencephalitis nodosa (Pette). Arch. f. Psychiat. 117:667, 1944.

32. Kalar, H.: Uber die Stellung der Panencephalitis (Pette-Döring) zur Leucoencéphalite sclérosante subaiguë (van Bognert). Deutsche Ztschr. Nervenh. 169: 89,1952

33. Alajounine, T., Behtrand, I., Gruneh, J., and Fuavigny, H.: Fincéphalite nodulaire à évolution subaiguë associée à des signes anatomo-clinique de polynevrite. Rev. neurol. 95:20, 1956.

34. Alajouanine, T., Ghuneh, J., Goulon, M., Nehlei, J., and Lior, F.: Panencéphalite avec necrose étendue de la substance blanche (les rapports avec la leucoencéphalite sclérosante subaiguë de van Bogaert). Rev. neurol. 95:357, 1956.

35. Mattyus, A.: Zur Kenntnis der subacuten Panencephalitiden. Deutsche Ztschr. Nervenh. 176:1, 1957.

36. Gagnon, J., Countors, A., and Duchastel, Y.: Encéphalite subaiguë à inclusion. Ses rapports avec la panencéphalite noduleuse et la leucoencéphalite sclérosante subaiguë. Union méd. Canada 88:921, 1959.

37. Schlange, H.: Bejtrag zur Klinik der Panencephalitiden. Monatsschr. Kinderh, 107:367, 1959.

38. Tariska, S.: Zur Pathologie der subakuten progressiven Panencephalitiden. Deutsche Ztschr. Nervenh. $179: 363,1959$.

39. Hasslen, R.: The pathological and pathophysiological basis of tremor and Parkinsonism. Prooeedings of the Second International Congress of Neuropathology, London, 1955.

40. Guazzi, G. C.: La topographie des lesions du tronc cérébral et de la moelle dans la leucoencéphalite sclérosante subaiguë, d'après $\mathbf{5 0}$ cas anatomiques. Proceedings of Antwerp Symposium on Encephalitis, in press.

41. van Bogakrt, L.: Personal communication, 1960.

42. Coers, C., Kleyntjens, F., and Bhihaye, J.: Syndrome parkinsonien d'origine tumorale. Acta neurol. et psychiat, belg. $52: 737,1952$

43. van Bogafrt, L.: Die klinische Einheit und die pathologische Variationsbreite der subakuten sklerosierenden Leuko-encephalitis. Wien. Ztschr. Nervenh. $13: 185,1957$

44. Poser, C. M., and van Bogaert, L.: Natural history and evolution of the concept of Schilder's diffuse sclerosis. Acta psychiat. et neurol. scandinav. 31:285, 1956.

45. Radermeckeh, J., and Macken, J.: Aspects électroencéphalographiques et cliniques de la leucoencéphulite sclérosante subaiguë. Rev. neurol. 85:341, 1951.

Printed in U.S.A. 